\title{
Multifunctional analysis of antigen-specific T cells: correlates of vaccine efficiency
}

\author{
Mario Roederer \\ From Immunodiagnosis of Tuberculosis: New Questions, New Tools \\ Virginia, VA, USA. 21-23 September 2008
}

A new era for vaccine development and evaluation has begun with vaccines that generate cellular immune responses. If vaccine development is going to successfully engender $\mathrm{T}$-cell responses for vaccine protection, researchers must consider that $\mathrm{T}$-cells are capable of a large repertoire of cellular functions and then decide which functions they want to engage. The functions include killing by CD8 and CD4 T-cells, proliferation, and secretion of effector molecules (cytokines) that orchestrate immune responses, induction of inflammation and killing of target cells.

Using flow cytometry, functions can be measured on a cell-by-cell basis to quantify the different types of effector T-cells present. Findings in HIV and Hepatitis B vaccine research may inform vaccine work for TB. For example, an analysis of the Hepatitis B booster vaccine showed the current practice of measuring a single parameter to test vaccine efficiency is not sufficient. Measurement of IFN- $\gamma$ and IL- 2 produced by CD4 $\mathrm{T}$-cells showed that many antigen-specific T-cells made IL- 2 but not IFN- $\gamma$. In fact, only about half of the $\mathrm{T}$-cells responding to the vaccine produced IFN- $\gamma$ and so if only this cytokine was measured, the magnitude of the vaccine response would be undercounted by a factor of two. Further, when five cell functions were measured in HIV-infected progressors and non-progressors no single measurement identified the majority of HIV-specific CD4 T-cells. MIP-1Beta dominated CD8 T-cell response and long-term non-progressors seemed to have slightly greater cytokine responses overall. Analyzing cytokines by each T-cell subset showed that HIV-specific CD8+ $\mathrm{T}$-cells appear to be multifunctional; the magnitude of the overall CD8+ T-cell response to HIV does not

Correspondence: roederer@nih.gov

Vaccine Research Center, National Institutes of Health, Bethesda, Maryland, USA correlate with protection from disease progression, but long-term non-progressors maintain higher levels of polyfunctional (IL-2+, TNF-a + and IFN-g+) HIV-specific CD8+ T-cells than progressors; and polyfunctional T-cells correlate inversely with viral load. These findings define a correlate of protection against which vaccines may be evaluated.

Flow cytometry is the only platform that can provide multi-parametric analysis of the immune responses necessary for the most sensitive quantification of immunogenicity, identification of functional correlates, and adequate comparison of different regimens. In fact, flow cytometry is fundamentally changing vaccine development in terms of measuring cell response.

Published: 17 December 2010

doi:10.1186/1753-6561-4-S3-018

Cite this article as: Roederer: Multifunctional analysis of antigen-specific T cells: correlates of vaccine efficiency. BMC Proceedings 2010 4(Suppl 3): 018.

Submit your next manuscript to BioMed Central and take full advantage of:

- Convenient online submission

- Thorough peer review

- No space constraints or color figure charges

- Immediate publication on acceptance

- Inclusion in PubMed, CAS, Scopus and Google Scholar

- Research which is freely available for redistribution
Biomed Central 